\title{
How Do Pharmacists Assist Medicare Beneficiaries with Limited Income? A Cross-Sectional Study of Community Pharmacies in Alabama
}

\author{
Salisa C. Westrick, PhD; Tessa J. Hastings, MS; Stuart J. McFarland; \\ Lindsey A. Hohmann, PharmD; and Natalie S. Hohmann, PharmD
}

\begin{abstract}
BACKGROUND: Many Medicare beneficiaries have limited income and report problems paying for their medications. Programs are available to assist these low-income individuals. However, these programs are underused because of lack of general awareness and perceived complexity of program applications.
\end{abstract}

OBJECTIVES: To (a) determine the frequency of encounters by pharmacists with Medicare beneficiaries who cannot afford prescription drugs; (b) identify strategies that pharmacists use to assist Medicare beneficiaries who cannot afford prescription drugs; and (c) explore what pharmacists know about programs for Medicare beneficiaries with limited income.

METHODS: This study used a mixed-mode survey of 350 randomly sampled community pharmacies located in 32 counties in Alabama with a high proportion of Medicare beneficiaries who were potentially eligible for lowincome subsidy programs. Measures included frequency of encounters by pharmacists with Medicare beneficiaries who could not afford their medications, strategies used to assist Medicare beneficiaries, and pharmacists' knowledge of programs for Medicare beneficiaries with limited income.

RESULTS: Of 350 surveys sent, 12 were nondeliverable, and 151 were completed (response rate $=44.6 \%$ ). About $50 \%$ of respondents reported encountering Medicare beneficiaries who could not afford their medications at least weekly. Various strategies were reported, including refiling claims that were previously denied every day $(40.7 \%)$, contacting insurance companies at least once per week (43.2\%), and loaning medications at least 2-3 times per month $(29.1 \%)$. Only $12.6 \%$ reported referring beneficiaries to the Aging and Disability Resource Centers (ADRCs) to assess eligibility for limitedincome programs. When asked about programs for beneficiaries with limited income, the answers were predominantly "don't know for sure."

CONCLUSIONS: Several strategies were used by pharmacists in an attempt to help limited-income Medicare beneficiaries obtain their medications. Lack of knowledge about financial assistance programs for limited-income individuals and the role of ADRCs in helping to screen individuals for benefits and complete applications warrants immediate attention. Improving pharmacists' knowledge on this topic may be an effective mechanism for providing a long-term solution for their patients.

J Manag Care Spec Pharm. 2016;22(9):1039-45

Copyright $@ 2016$, Academy of Managed Care Pharmacy. All rights reserved.

\section{What is already known about this subject}

While Medicare Part D helps Medicare beneficiaries afford their medications, many still have problems paying for their prescriptions Programs are available to assist Medicare beneficiaries with limited income, but they are underused.

\section{What this study adds}

This study demonstrates that pharmacists frequently encounter limited-income Medicare beneficiaries and are ideally positioned to identify and refer potentially eligible individuals to resource agencies for benefits screening.

Providing pharmacists with education to improve their knowledge of available subsidy programs and efficient referral processes will help beneficiaries with limited income to better use available resources.

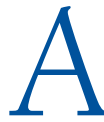
s of 2014, more than 37 million seniors, defined as individuals aged 65 years or older, were enrolled in a Medicare prescription drug plan, otherwise known as Medicare Part D. ${ }^{1}$ Medicare Part D, a voluntary benefit offered by private insurance companies, provides coverage for a portion of direct medication costs, as well as subsidized premiums, to make coverage more affordable for beneficiaries. When Medicare Part D was initiated in January 2006 to help cover the medication costs of Medicare beneficiaries, prescription drug coverage increased from 59\% to 89\% for beneficiaries. ${ }^{2}$ While Part D helps Medicare beneficiaries afford their prescriptions, many beneficiaries still report problems paying for their medications. ${ }^{3}$

Medicare beneficiaries are more likely to have limited income than the population under aged 65 years. In 2014 the median annual income of seniors was $\$ 36,895$, compared with $\$ 60,462$ for individuals under the age of $65 .{ }^{4}$ In addition, Medicare beneficiaries spend a greater proportion of their income on health care costs (14\%) than those under the age of $65(5 \%) .^{5}$ The cost of health care forces many limited-income Medicare beneficiaries to choose between basic needs, such as groceries and rent, and their medications. Specifically, 11\% of Medicare beneficiaries reported spending less on basic needs so that they could afford their prescriptions, and 14\% reported taking less medication than prescribed or not filling their prescriptions at all because of costs. ${ }^{6}$ This is a major public health problem, since research studies consistently show that unaffordable medications can lead to medication nonadherence, which leads to increased rates of hospitalization, morbidity, and mortality. ${ }^{7-11}$ 
Several programs are available to assist Medicare beneficiaries with limited income. These programs can help with health care affordability, which may subsequently reduce cost-related nonadherence and its undesirable consequences. Examples of these programs include the Medicare Savings Programs (MSPs) and the Low-Income Subsidy (LIS), also known as Extra Help. Eligibility for MSPs varies by state and is updated yearly. When determining if an individual meets requirements for these programs, monthly income and, in some cases, resources (e.g., savings accounts, stocks, bonds, and retirement accounts) must be considered. Benefits of these programs are tremendous. Medicare Part B premiums (\$104.90 per month in 2015) are waived for MSP enrollees, who are are also automatically enrolled in LIS. LIS provides full or partial coverage of many Part D cost-sharing requirements such as premiums, deductibles, copayments, and cost sharing in the coverage gap. The average annual value of the LIS benefit alone was estimated to be approximately $\$ 4,000$ per beneficiary in 2011. ${ }^{12}$ Therefore, successful enrollment in an MSP and/or the LIS helps Medicare beneficiaries reduce this economic burden.

Although these programs have the potential to greatly assist many low-income beneficiaries, they are underused. Many individuals are eligible, but approximately $60 \%$ of those eligible for the LIS have not enrolled. ${ }^{13}$ Much of this low enrollment problem is because of lack of awareness; about $68 \%$ of lowincome seniors are not aware of available subsidy programs. ${ }^{14}$ In addition, the enrollment process itself can be difficult and confusing. Agencies such as the Aging and Disability Resource Centers (ADRCs) and State Health Insurance Assistance Program (SHIP) are available in every state to assist individuals with screening and filling out applications for these programs. Despite the services provided by these agencies, many potentially qualified seniors remain unaware of these services. To increase the awareness among the hard-to-reach beneficiaries, health care providers play an important part in identifying and referring potentially eligible individuals for benefits screening at ADRCs and/or SHIP.

There are several groups of health care providers that Medicare beneficiaries encounter during the course of their illnesses, including physicians, nurses, and pharmacists. Research studies have found that many patients do not discuss their concerns regarding medication costs with their physicians..$^{15,16}$ Since pharmacists interact with patients when dispensing medications, they often assist patients with insurance-related problems and/or concerns regarding medication costs. ${ }^{17-20}$ Given the accessibility and availability of pharmacists, their experiences dealing with insurance plans, and frequent patient visits to pharmacies, pharmacists are in an ideal position to serve as frontline health care professionals who can identify and refer potentially eligible individuals. To be effective, pharmacists should first be aware of programs available for limitedincome individuals. However, little is known about pharmacist knowledge relating to Medicare and available programs for limited-income beneficiaries and the extent to which pharmacists assist such Medicare beneficiaries. Therefore, the objectives of this study were to (a) determine frequency of encounters by pharmacists with Medicare beneficiaries who cannot afford prescription drugs; (b) identify strategies that pharmacists use to assist Medicare beneficiaries who cannot afford prescription drugs; and (c) explore what pharmacists know about programs for Medicare beneficiaries with limited income.

\section{Methods}

\section{Study Design and Sample}

This study used a cross-sectional survey design. The overall goal of the study was to describe how, and to what extent, community pharmacists assisted Medicare beneficiaries who could not afford their prescription medications. The unit of analysis was at the pharmacy level, and information was gathered from key informants of community pharmacies, which included pharmacy managers or other staff pharmacists to whom the managers delegated the responsibility. The study protocol was reviewed and approved by the authors' institutional review board as expedited review.

Community pharmacies were randomly selected from 32 counties, of 67 counties, in Alabama. These 32 counties were selected based on high percentage of potentially eligible individuals who may have qualified for but did not enroll in the Medicare LIS programs. These data were provided by the National Council on Aging. ${ }^{13}$ To select community pharmacies, the Hayes Directory Database was used as a sampling frame, which provided community pharmacy names, mailing addresses, county name, telephone numbers, and fax numbers. Of the 681 community pharmacies in these 32 counties, 350 were randomly selected and served as this study's sample. The decision to invite 350 pharmacies was made after careful consideration of survey costs and survey errors as we attempted to optimize the balance of these 2 factors. Based on our previous survey studies with community pharmacies, we anticipated response rates to fall between $30 \%-40 \%$, which would result in an expected sample size of 105-140.21,22 With the confidence level of $95 \%$, such sample size would yield a range of margins of error between 7.4-8.8 percentage points, which was deemed acceptable.

The survey was conducted from June 2015 to August 2015 using a modified Dillman's Tailored Design Method. ${ }^{23}$ The survey consisted of 5 contacts: a prenotification postcard, a survey packet, a reminder postcard, a reminder phone call, and a replacement survey packet. Mail contacts were sent via first-class mail, and reminder telephone calls were made with a limit of 5 call attempts per pharmacy. Each survey packet included an invitation letter, an information letter, the 4-page questionnaire, and a stamped and pre-addressed return envelope. In all contacts, instructions on how to complete the 
survey electronically, as an alternative mode, were also provided. Each participant had the opportunity to win one of five $\$ 100$ cash prizes.

\section{Survey Variables and Measures}

The survey consisted of 41 questions (see Appendix, available in online article) divided among several sections, including (a) Medicare Population and Pharmacy Services for Medicare Enrollees, (b) Awareness and Knowledge of Community Resources and Assistance Programs, and (c) Pharmacist and Practice Site Information. One open-ended question in the Medicare Population and Pharmacy Services section allowed the respondents to freely describe what they do when they encounter elderly or disabled individuals who cannot afford their prescription medications. After the open-ended question, respondents were asked to indicate the frequency of various strategies (e.g., loaning medications and contacting prescribers) when interacting with limited-income Medicare patients. Respondents were instructed to select how often they used these strategies during the past 6 months, with 7 response categories ranging from "never" to "daily." The next section, consisting of 15 questions, assessed knowledge about Medicare, subsidy programs, and community resources. Response categories were "true," "false," and "don't know for sure." The following are examples of the knowledge questions: "The Medicare Savings Program is the same as a Medicare Savings Account" and "In Alabama, LIS has both income and asset eligibility limits." The rest of the survey gathered respondents' demographic information (education, sex, race, and pharmacy) and practice site characteristics (prescription volume, technicians, and pharmacists employed).

\section{Pretesting}

The survey questions were written and refined by the research team. To ensure the content validity of survey questions, the research team consulted with the director of Alabama's SHIP, 2 SHIP counselors, and a licensed pharmacist, who was a graduate student in the authors' pharmacy school department. After changes were made, the questionnaire was pretested with 7 community pharmacists in Alabama in order to assess the face validity of the measures. Based on their feedback, minor modifications were made.

\section{Nonresponse Bias Investigation}

After the data collection was concluded, 30 community pharmacies that did not respond to the survey requests were randomly selected. These pharmacies were contacted via telephone, with 5 maximum contacts, and were requested to respond to these 5 key questions: (1) What is the percentage of your patients who have Medicare as their primary insurance? (2) How often does the pharmacy staff encounter Medicare patients who cannot afford their medications? (3) How often does the pharmacy staff refer Medicare patients to the ADRC, area agencies on aging, or SHIP? (4) How many staff pharmacists are employed at your practice site? and (5) What is the average prescription volume per day at your practice site? To analyze differences between respondents and nonrespondents, response categories were merged to ensure that the frequency in each cell was at least 5 . For example, the question regarding the percentage of patients that have Medicare as their primary insurance was merged from 5 categories: $0 \%-10 \%, 11 \%-25 \%, 26 \%-50 \%, 51 \%-75 \%$, and $76 \%-100 \%$ to 2 categories: $0 \%-50 \%$ and $51 \%-100 \%$. Nonrespondent responses to each of the above questions were then compared with respondent responses to assess any differences. Nineteen pharmacies participated in the nonresponse bias telephone interviews.

\section{Data Analysis}

Data were analyzed using the Statistical Package for the Social Sciences (SPSS) version 21.0 (IBM Corp., Armonk, NY). Descriptive statistics were used to describe respondent characteristics, frequency of encounters and strategies used by pharmacists when interacting with Medicare beneficiaries who could not afford medications, and respondent knowledge of Medicare, Medicare subsidy programs, and community resources.

As for the open-ended question asking respondents to describe what they do when they encounter elderly or disabled individuals who cannot afford their prescription medications, the research team reported frequencies of each strategy and then classified the responses into whether the action was taken on behalf of patients by the pharmacist, such as when a pharmacist conducted a search for assistance through manufacturer programs. In contrast, actions that did not fit this category included pharmacists suggesting that beneficiaries should select a different prescription drug plan and recommending that beneficiaries call Medicare. Nonresponse bias was investigated by comparing answers of respondents and nonrespondents using one-way analysis of variance for continuous variables and chi-square tests for categorical variables. A significance level of 0.05 was used for statistical analysis.

\section{Results}

Of the 350 surveys, 12 were returned as undeliverable, and 151 completed surveys were returned. The 151 responses included 98 paper surveys and 53 electronic surveys. The overall response rate was $44.6 \%$. With the confidence level of $95 \%$, the population of 681 , and the sample size of 151 , the margin of error was determined to be $7 \%$. The nonresponse bias investigation did not reveal statistically significant differences between respondents and nonrespondents.

Regarding respondent characteristics, the majority were white (93.2\%) and female (55.0\%). About 55\% of participants indicated that they had a PharmD degree, while less than half (46.4\%) 


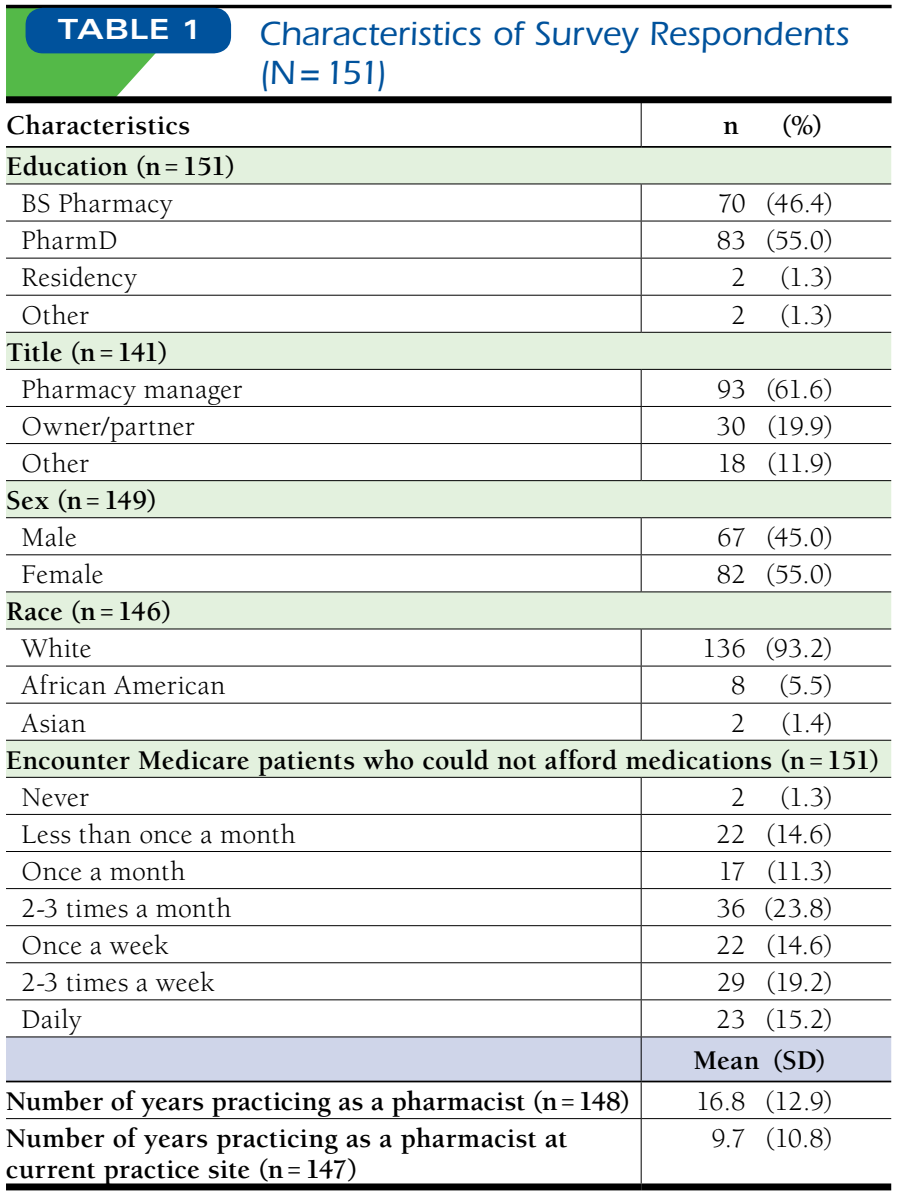

had a BS Pharmacy degree. The participants were pharmacy managers (61.6\%), owners or partners (19.9\%), or other (11.9\%). Those classified as "other" included staff pharmacists and assistant pharmacy managers. Approximately $50 \%$ of respondents reported encountering Medicare patients who could not afford their medications at least once a week. On average, participants had been practicing as pharmacists for 16.8 years, with an average of 9.7 years practicing at their current site (Table 1).

In an open-ended question eliciting actions by pharmacists when encountering elderly or disabled individuals who cannot afford their prescription medications, $81.9 \%$ reported taking action on behalf of the patient (Table 2). The most frequently reported actions included changing the prescription to a lowercost medication (63.8\%); searching for assistance through manufacturer or community programs (43.5\%); loaning or giving away medications (26.8\%); and suggesting that the patient contact an agency such as Medicare, Medicaid, Social Services, or the Social Security Administration (22.5\%). Less frequently reported actions included prioritizing medications or helping the patient search for a new plan.

\section{TABLE 2 \\ Actions of Pharmacists When Encountering Elderly or Disabled Individuals Who Could Not Afford Prescription Medications}

\begin{tabular}{|c|c|}
\hline & n $(\%)$ \\
\hline \multicolumn{2}{|l|}{ Action $^{a}(n=149)$} \\
\hline Change to a lower-cost medication & $88(63.8)$ \\
\hline $\begin{array}{l}\text { Search for assistance from manufacturer or } \\
\text { community programs }\end{array}$ & $60(43.5)$ \\
\hline Loan or give away medications & $37(26.8)$ \\
\hline $\begin{array}{l}\text { Suggest other agencies (Medicare, Medicaid, } \\
\text { Social Services, or Social Security) }\end{array}$ & $31(22.5)$ \\
\hline Help patients search for new coverage plan & $9(6.5)$ \\
\hline Sign patient up for store discount card or program & $7(5.1)$ \\
\hline Fill a portion of prescription medication & $5(3.6)$ \\
\hline Contact prescription drug plan & $2(1.4)$ \\
\hline Change the price & $1(0.7)$ \\
\hline $\begin{array}{l}\text { Send patient to another pharmacy that may sell } \\
\text { the medication at a lower cost }\end{array}$ & $1(0.7)$ \\
\hline Prioritize medications (fill most important) & $1(0.7)$ \\
\hline \multicolumn{2}{|c|}{ Whether the respondent took action on behalf of patient ${ }^{b}$} \\
\hline Yes & $113(81.9)$ \\
\hline No & $24(17.4)$ \\
\hline
\end{tabular}

Pharmacists reported undertaking a wide range of strategies to assist these patients (Table 3): $40.7 \%$ of pharmacists reported filing claims with Medicare that had previously been denied every day; $43.2 \%$ reported contacting the insurance company to see if they would cover the medication at least once a week; and $46.4 \%$ searched for free or low-cost medications from community or manufacturer programs at least once a week.

With regard to the knowledge questions about Medicare and programs for limited-income beneficiaries, the majority of pharmacists answered questions concerning Medicare payment for influenza and pneumococcal vaccines (89.9\%) and herpes zoster vaccine (73.0\%) correctly. When asked if LIS will lower Medicare Part D premiums for eligible individuals, about half (50.3\%) answered correctly. However, the remaining questions in the survey were predominantly answered with "Don't know for sure" (Table 4). These questions were predominantly about MSPs, roles of ADRCs and SHIP, and medication assistance programs (e.g., SenioRx program).

\section{Discussion}

It is estimated that 7.2 million of 37 million Medicare beneficiaries have limited income, with many beneficiaries reporting not filling prescriptions, taking less of a prescribed medication, or cutting back on basic needs because of medication costs. ${ }^{1,6,24}$ Combined with increased hospitalizations, morbidity, mortality, and health care costs resulting from cost-related 
TABLE 3 Frequency of Pharmacist Actions When Interacting with Medicare Patients During the Past 6 Months $(\mathrm{N}=151)^{\mathrm{a}}$

\begin{tabular}{|c|c|c|c|c|c|c|c|}
\hline & Never & $\begin{array}{l}\text { Less Than } \\
\text { Once } \\
\text { a Month }\end{array}$ & $\begin{array}{l}\text { Once } \\
\text { a Month }\end{array}$ & $\begin{array}{l}\text { 2-3 Times } \\
\text { per Month }\end{array}$ & $\begin{array}{c}\text { Once } \\
\text { a Week }\end{array}$ & $\begin{array}{l}\text { 2-3 Times } \\
\text { a Week }\end{array}$ & Daily \\
\hline & n $\quad(\%)$ & n $\quad(\%)$ & n $\quad(\%)$ & n $\quad(\%)$ & n $\quad(\%)$ & n $\quad(\%)$ & n $\quad(\%)$ \\
\hline $\begin{array}{l}\text { File claims with Medicare prescription drug plans that were } \\
\text { previously denied }(\mathrm{n}=150)\end{array}$ & $25(16.7)$ & $8 \quad(5.3)$ & $8 \quad(5.3)$ & $11(7.3)$ & $13(8.7)$ & $24(16.0)$ & $61(40.7)$ \\
\hline $\begin{array}{l}\text { Contact prescribers to change to a lower-cost medication } \\
(\mathrm{n}=151)\end{array}$ & $1 \quad(0.7)$ & $7 \quad(4.6)$ & $12(7.9)$ & $31(20.5)$ & $28(18.5)$ & $41(27.2)$ & $31(20.5)$ \\
\hline $\begin{array}{l}\text { Contact insurance plans to ask if they could cover a } \\
\text { medication }(n=146)\end{array}$ & $26(17.8)$ & $21(14.4)$ & $11 \quad(7.5)$ & $25(17.1)$ & $15(10.3)$ & $20(13.7)$ & $28(19.2)$ \\
\hline $\begin{array}{l}\text { Search for free or low-cost medications from manufacturers } \\
\text { or community programs }(n=151)\end{array}$ & $15 \quad(9.9)$ & $26(17.2)$ & $23(15.2)$ & $17(11.3)$ & $22(14.6)$ & $22(14.6)$ & $26(17.2)$ \\
\hline $\begin{array}{l}\text { Only fill the portion of a prescription that a patient } \\
\text { could pay for }(n=151)\end{array}$ & $8 \quad(5.3)$ & $21(13.9)$ & $20(13.2)$ & $36(23.8)$ & $26(17.2)$ & $22(14.6)$ & $18(11.9)$ \\
\hline $\begin{array}{l}\text { Refer Medicare patients to ADRC or SHIP to determine } \\
\text { eligibility for benefits from community programs }(n=151)\end{array}$ & $75(49.7)$ & $29(19.2)$ & $16(10.6)$ & $12(7.9)$ & $6 \quad(4.0)$ & $6 \quad(4.0)$ & $7 \quad(4.6)$ \\
\hline Loan or give away medications $(n=151)$ & $65(43.0)$ & $32(21.2)$ & $10 \quad(6.6)$ & 18 (11.9) & $12 \quad(7.9)$ & $13 \quad(8.6)$ & $1 \quad(0.7)$ \\
\hline
\end{tabular}

medication nonadherence, it is clear that medication-related financial assistance is a prevalent need among Medicare beneficiaries that has clinical and economic consequences. ${ }^{25}$ However, despite the availability of subsidies such as MSPs and LIS to financially assist these individuals, many beneficiaries do not receive this assistance because of lack of awareness. ${ }^{14,24,26}$ Pharmacists are in a good position to mitigate this problem by identifying potentially eligible individuals and referring them to resource agencies who can assess their eligibility for these programs. Pharmacists are highly accessible and have an expanding role in community health care. According to the Convenient Care Association, the number of clinics located in U.S. retail pharmacies doubled from the years 2007 to 2013, reaching 1,400. ${ }^{27}$ Most patients and physicians have already relied on pharmacists to reconcile cost issues that patients may have encountered. ${ }^{17,28}$ In order for pharmacists to effectively identify and refer potentially qualified individuals, however, they need to be equipped with the knowledge necessary to identify individuals and available programs. This study is the first identifiable study to report how pharmacists assist Medicare beneficiaries who could not afford to pay for their medications and their knowledge of Medicare, subsidy programs, and available community resources.

The results of this study show that pharmacists frequently encountered Medicare beneficiaries who could not afford their medications and employed a wide range of strategies to assist them. However, their limited knowledge of long-term solutions, such as subsidy programs, may have decreased the effectiveness of their strategies. Pharmacists most frequently employed short-term solutions, such as resubmitting previ- ously denied claims. Many pharmacists advised patients to contact Medicare or Medicaid but provided no other specifics. While some of these methods may result in potentially useful solutions, most are either time consuming for the pharmacist or difficult for the patient to complete. To most effectively assist limited-income beneficiaries in finding affordable coverage and reducing out-of-pocket costs, it is essential that pharmacists are properly equipped with the knowledge and the means.

Many Medicare beneficiaries are facing unaffordable health care costs. Health spending per capita among Medicare beneficiaries was $\$ 10,365$ per year in 2009 , and out-of-pocket spending per capita was $\$ 4,700$ in premiums, cost sharing for Medicare-covered benefits, and costs for services not covered by Medicare in 2010,5,29 This expenditure places a heavy burden on many beneficiaries, especially considering that 1 out of 3 Medicare beneficiaries was considered low income $(<200 \%$ of federal poverty level) in $2014 .^{30}$ Several federal and state programs are available to help individuals with limited income, including the LIS program (or Extra Help) and MSPs. In addition, each state has programs that provide assistance to those who may not meet income and/or resource eligibility of the LIS and MSP programs, such as the SenioRx program in Alabama. Savings received from enrolling in these programs can be substantial. Despite the availability of these subsidy programs, many eligible individuals have not enrolled in these programs. In Alabama, many eligible individuals have not yet enrolled in the MSP and LIS programs. ${ }^{13}$ 
TABLE 4 What Pharmacists Know About Medicare, Programs for Low-Income Beneficiaries, and Community Resources $(\mathrm{N}=151)^{\mathrm{a}}$

\begin{tabular}{|c|c|c|c|c|}
\hline & & $\begin{array}{l}\text { Correct } \\
\text { Answer }\end{array}$ & $\begin{array}{l}\text { Incorrect } \\
\text { Answer }\end{array}$ & $\begin{array}{l}\text { Don't Know } \\
\text { for Sure }\end{array}$ \\
\hline & & & n $\quad(\%)$ & n $\quad(\%)$ \\
\hline Medicare Part B pays for influenza and pneumococcal vaccines $(n=149)$. & True & $134(89.9)$ & $0 \quad(0.0)$ & $15(10.1)$ \\
\hline Medicare Part D plans cover herpes zoster vaccine $(n=148)$. & True & $108(73.0)$ & $20(13.5)$ & $20(13.5)$ \\
\hline LIS will lower Medicare Part D premiums for eligible individuals $(n=149)$. & True & $75(50.3)$ & $3(2.0)$ & $71(47.7)$ \\
\hline In Alabama, LIS has both income and asset eligibility limits $(n=150)$. & True & $63(42.0)$ & $2(1.3)$ & $85(56.7)$ \\
\hline $\begin{array}{l}\text { Annual wellness visits require no copayments from Medicare enrollees if they enroll in } \\
\text { Medicare Part B ( } \mathrm{n}=148) \text {. }\end{array}$ & True & $59(39.9)$ & $5(3.4)$ & $84(56.8)$ \\
\hline ADRC conduct benefits screening for MSP, LIS, and SenioRx programs $(\mathrm{n}=150)$. & True & $54(36.0)$ & $1 \quad(0.7)$ & $95(63.3)$ \\
\hline $\begin{array}{l}\text { SHIP provides unbiased assistance with Medicare prescription drug plan evaluation and } \\
\text { selection }(n=150) \text {. }\end{array}$ & True & $51(34.0)$ & $2(1.3)$ & $97(64.7)$ \\
\hline The MSP is the same as a Medicare Savings Account $(n=150)$. & False & $39(26.0)$ & $3(2.0)$ & $108(72.0)$ \\
\hline ADRC conducts benefits screenings for the Alabama Elderly Nutrition Program $(n=150)$. & True & $35(23.3)$ & $1 \quad(0.7)$ & $114(76.0)$ \\
\hline The LIS, also known as Extra Help, is sponsored by Medicaid $(\mathrm{n}=150)$. & False & $33(22.0)$ & $33(22.0)$ & $84(56.0)$ \\
\hline $\begin{array}{l}\text { The late enrollment penalty for Medicare Part } D \text { will be added to a person's premium for a } \\
\text { maximum of } 24 \text { months }(n=150) \text {. }\end{array}$ & False & $30(20.0)$ & $34(22.7)$ & $86(57.3)$ \\
\hline Individuals must pay a nominal fee to ADRC to receive their assistance $(\mathrm{n}=150)$. & False & $28(18.7)$ & $6 \quad(4.0)$ & $116(77.3)$ \\
\hline Medicare Part D beneficiaries do not qualify for the SenioRx Program $(n=150)$. & False & $26(17.3)$ & $12(8.0)$ & $112(74.7)$ \\
\hline The MSP pays for Medicare Part B premiums $(\mathrm{n}=149)$ & True & $15(10.1)$ & $18(12.1)$ & $116(77.9)$ \\
\hline In Alabama, the MSP has both income and asset eligibility limits $(n=149)$. & False & $4(2.7)$ & $43(28.9)$ & $102(68.5)$ \\
\hline
\end{tabular}

Because the key reasons for low program enrollment include lack of awareness, complex eligibility rules, and cumbersome application processes,$^{31}$ there is a need to identify potentially eligible individuals and refer them to an agency that can assist individuals with completing applications. In several states, state and regional resource agencies have collaborated with local community and business partners, such as senior centers and pharmacies, to expand their reach to identify potentially qualified individuals who may be hard to reach. To do so effectively, partners should be knowledgeable about Medicare and subsidy programs, as well as the role of such agencies as ADRC and SHIP. The lack of knowledge among pharmacists related to available subsidy programs and the role of ADRCs, as reported in this study, warrants immediate attention to the need of an education program to improve pharmacists' knowledge of low-income assistance. This is the first step towards providing long-term, sustainable solutions for Medicare beneficiaries in need of assistance. Realizing this need, Alabama has recently launched an inititiative to provide a continuing education program for pharmacy personnel and establish a pharmacy network to identify and refer potentially qualified Medicare beneficiaries for benefits screenings by ADRCs.

\section{Limitations}

This study's limitations should be recognized. First, because this study used a cross-sectional design to describe pharmacist knowledge and encounters, no causal relationships can be inferred. Second, because this survey measured self-reported behaviors, social desirability and recall biases are possible. Third, the frequency of various strategies used is dependent on the frequency of pharmacist encounters with low-income Medicare beneficiaries. Fourth, inclusion was limited to community pharmacies in the state of Alabama with a high proportion of low-income beneficiaries, so the results may not be generalizable to other locations that may have different patient demographics. Fifth, participants who responded to the survey may differ from nonrespondents, although no statistically significant differences were found in the nonresponse bias investigation. Finally, this study did not assess if knowledge and referral of these programs by pharmacists leads to greater beneficiary enrollment and improved medication adherence or health outcomes.

\section{Conclusions}

Many low-income Medicare beneficiaries are in need of assistance in finding ways to afford their medications. Pharmacists, as the most accessible health care professionals, are well positioned to help these patients. However, what pharmacists know about available subsidy programs and community resources is limited. Thus, they often focus on short-term solutions. Providing pharmacists with educational opportunities to improve their knowledge related to these subsidies may help them effectively refer patients to resource agencies, which may result in long-term and effective solutions for Medicare beneficiaries. 


\section{How Do Pharmacists Assist Medicare Beneficiaries with Limited Income? A Cross-Sectional Study of Community Pharmacies in Alabama}

\section{Authors}

SALISA C. WESTRICK, PhD; TESSA J. HASTINGS, MS; STUART J. MCFARLAND; LINDSEY A. HOHMANN, PharmD; and NATALIE S. HOHMANN, PharmD, Health Outcomes Research and Policy, Harrison School of Pharmacy, Auburn University, Auburn, Alabama.

AUTHOR CORRESPONDENCE: Salisa C. Westrick, PhD, 020 James E. Foy Hall, Auburn University, Auburn, AL 36849. Tel.: 334.844.8314; Fax: 334.844.8307; E-mail: westrsc@auburn.edu.

\section{DISCLOSURES}

This study was funded by the Alabama Department of Senior Services. The sponsor played no active role in the design, methods, data collection, analysis, or preparation of this manuscript. The authors have nothing to disclose.

This paper was presented at the American Pharmacists Association meeting in Baltimore, Maryland, in 2016.

Study concept and design were contributed by Westrick. Hastings and McFarland were responsible for data collection, along with Westrick. Data interpretation was performed by Westrick, L. Hohmann, and Hastings, with assistance from McFarland. All authors were involved with manuscript preparation.

\section{REFERENCES}

1. Hoadley J, Summer L, Hargrave E. Medicare Part D in its ninth year: the 2014 marketplace and key trends, 2006-2014. Kaiser Family Foundation. August 18, 2014. Available at: http://kff.org/medicare/report/medicarepart-d-in-its-ninth-year-the-2014-marketplace-and-key-trends-2006-2014/. Accessed July 13, 2016.

2. Part D reduces hospitalizations for some conditions. Manag Care. 2011;20(8):57-57.

3. Briesacher BA, Ross-Degnan D, Wagner AK, et al. Out-of-pocket burden of health care spending and the adequacy of the Medicare Part D lowincome subsidy. Med Care. 2010;48(6):503-09.

4. DeNavas-Walt C, Proctor BD, U.S. Census Bureau. Income and poverty in the United States: 2014. Current Population Reports, P60-252. U.S. Government Printing Office. Washington, DC. 2015. Available at: https:// www.census.gov/content/dam/Census/library/publications/2015/demo/p60252.pdf. Accessed July 13, 2016.

5. Cubanski J, Swoope C, Damico A, Neuman T. Health care on a budget: the financial burden of health spending by Medicare households. Kaiser Family Foundation. January 9, 2014. Available at: http://files.kff.org/attachment/issue-brief-health-care-on-a-budget-the-financial-burden-of-healthspending-by-medicare-households. Accessed July 13, 2016.

6. Madden JM, Graves AJ, Zhang F, et al. Cost-related medication nonadherence and spending on basic needs following implementation of Medicare Part D. JAMA. 2008;299(16):1922-28.

7. Johnson RE, Goodman MJ, Hornbrook MC, Eldredge MB. The impact of increasing patient prescription drug cost sharing on therapeutic classes of drugs received and on the health status of elderly HMO members. Health Serv Res. 1997;32(1):103-22.

8. Tamblyn R, Laprise R, Hanley JA, et al. Adverse events associated with prescription drug cost-sharing among poor and elderly persons. JAMA. 2001;285(4):421-29.

9. Chandra A, Gruber J, McKnight R. Patient cost-sharing and hospitalization offsets in the elderly. Am Econ Rev. 2010;100(1):193-213.

10. Lurie N, Ward NB, Shapiro MF, Gallego C, Vaghaiwalla R, Brook RH. Termination of Medi-Cal benefits. A follow-up study one year later. N Engl J Med. 1986;314(19):1266-68.
11. Goldman DP, Joyce GF, Zheng Y. Prescription drug cost sharing: associations with medication and medical utilization and spending and health. JAMA. 2007;298(1):61-69.

12. Summer L, Hoadley J, Hargrave E. The Medicare Part D low-income subsidy program: experience to date and policy issues for consideration. Kaiser Family Foundation. September 1, 2010. Available at: http://kff.org/ medicare/issue-brief/the-medicare-part-d-low-income-subsidy/. Accessed July 13, 2016.

13. National Council on Aging. Visualization tools: mapping access to benefits for people with Medicare. 2016. Available at: http://www.ncoa.org/ enhance-economic-security/center-for-benefits/visualizing-lis-eligibility. html?utm_source=BenefitsAlert_140618\&utm_medium=newsletter\&utm _ campaign=BenefitsAlert. Accessed July 13, 2016.

14. Alston G, Hanrahan C. Can a pharmacist reduce annual costs for Medicare Part D enrollees? Consult Pharm. 2011;26(3):182-89.

15. Wilson IB, Schoen C, Neuman P, et al. Physician-patient communication about prescription medication nonadherence: a 50-state study of America's seniors. J Gen Intern Med. 2007;22(1):6-12.

16. Piette JD, Heisler M, Wagner TH. Cost-related medication underuse: do patients with chronic illnesses tell their doctors? Arch Intern Med. 2004;164(16):1749-55.

17. Khan S. Medicare Part D: pharmacists and formularies-whose job is it to address copays? Consult Pharm. 2014;29(9):602-13.

18. Radford A, Mason M, Richardson I, et al. Continuing effects of Medicare Part D on rural independent pharmacies who are the sole retail provider in their community. Res Social Adm Pharm. 2009;5(1):17-30.

19. Khan S. Urban and suburban community pharmacists' experiences with Part D—a focus group study. J Pharm Technol. 2012;28(6):249-57.

20. Bono JD, Crawford SY. Impact of Medicare Part D on independent and chain community pharmacies in rural Illinois-a qualitative study. Res Social Adm Pharm. 2010;6(2):110-20.

21. Westrick SC, Breland ML. Sustainability of pharmacy-based innovations: the case of in-house immunization services. J Am Pharm Assoc (2003). 2009;49(4):500-08

22. Westrick SC, Mount JK. Impact of perceived innovation characteristics on adoption of pharmacy-based in-house immunization services. Int J Pharm Pract. 2009;17(1):39-46.

23. Dillman DA. Mail and Internet Surveys: The Tailored Design Method-2007 Update with New Internet, Visual, and Mixed-Mode Guide. Hoboken, NJ: John Wiley \& Sons; 2007.

24. Many seniors not getting low-income subsidies for medicine. State News (Council of State Governments). 2006;49(6):5-5.

25. Eaddy MT, Cook CL, O'Day K, Burch SP, Cantrell CR. How patient cost-sharing trends affect adherence and outcomes: a literature review. PT. 2012;37(1):45-55.

26. Zuckerman S, Shang B, Waidmann T. Medicare savings programs: analyzing options for expanding eligibility. Inquiry. 2009;46(4):391-404.

27. Robeznieks A. Retail clinics at tipping point. Pharmacies, chains answering demand for access and affordability. Mod. Healthc. 2013;43(18):6-7, 16, 11.

29. Shrank WH, Young HN, Ettner SL, Glassman P, Asch SM, Kravitz RL. Do the incentives in 3-tier pharmaceutical benefit plans operate as intended? Results from a physician leadership survey. Am J Manag Care. 2005;11(1):16-22.

29. Cuckler G, Martin A, Whittle L, et al. Health spending by state of residence, 1991-2009. Medicare Medicaid Res Rev. 2011;1(4):E1-E31.

30. Jacobson G, Swoope C, Neuman T, Smith K. Income and assets of Medicare beneficiaries, 2014-2030. Issue Brief. September 2015. Kaiser Family Foundation. Available at: http://files.kff.org/attachment/issue-brief-income-andassets-of-medicare-beneficiaries-2014-2030. Accessed July 13, 2016.

31. Medicare Payment Advisory Commission. Report to the Congress: Medicare payment policy. March 2008. Available at: http://medpac.gov/documents/reports/mar08_entirereport.pdf?sfvrsn=0. Accessed July 13, 2016. 


\section{How Do Pharmacists Assist Medicare Beneficiaries with Limited Income? \\ A Cross-Sectional Study of Community Pharmacies in Alabama}

\section{APPENDIX Study Survey}

Promoting Access to Community Resources for Medicare Patients: A Survey of Alabama Pharmacies

Introduction: Pharmacists in community pharmacies interact with aging/disabled individuals and their caregivers on a frequent basis. Since pharmacists are some of the most trusted healthcare resources in the community, patients may seek your advice when selecting health plans and applying for assistance programs to reduce healthcare costs. This questionnaire assesses how your pharmacy assists Medicare patients, especially those who have limited income, and your awareness of community resources for the Medicare population.

\section{Part I: Medicare Population and Pharmacy Services for Medicare Enrollees}

Instructions: Select the best answer $(\nabla)$ for each of the following questions.

1. About what percentage of your patients have Medicare as their primary insurance?
$\square 0-10 \%$
$\square 11-25 \%$
$\square 26-50 \%$
$\square 51-75 \%$
$\square 76-100 \%$

2. In 2014, did your pharmacy provide face-to-face comprehensive medication reviews (CMRs) for patients with Medicare prescription drug plans?

$\square$ No

$\square$ Yes

$\rightarrow$ please indicate the number of CMRs completed in 2014

3. In 2014, did your pharmacy provide targeted medication reviews (TMRs) for patients with Medicare prescription drug plans?

$\square$ No

$\square$ Yes

$\rightarrow$ please indicate the number of TMRs completed in 2014

4. In 2014, how many doses of the following vaccines were administered in your pharmacy?

Influenza vaccine

Pneumococcal vaccine

Hepatitis B vaccine

Herpes Zoster vaccine

5. During the Medicare open enrollment period (October 15-December 7) in 2014, how often did you and/or your pharmacy staff assist Medicare enrollees evaluating prescription drug plans?

$\square$ Never

$\square$ 1-6 times per week

$\square$ Less than 1 time per month

$\square$ 1-2 times per day $\square$ 1-4 times per month

$\square 3$ or more times per day

6. When you encounter elderly or disabled individuals who cannot afford their prescription medications, what do you do?

7. The following questions ask for the frequency of various events when interacting with Medicare patients. Select how often you encountered the following events during the past 6 months.

\begin{tabular}{|c|c|c|c|c|c|c|c|}
\hline During the past 6 months, how often did you or your pharmacy staff... & $\grave{\grave{J}}$ & 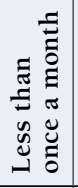 & 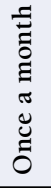 & 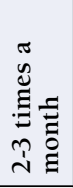 & $\begin{array}{l}\dddot{\Xi} \\
\tilde{J} \\
\tilde{J} \\
\tilde{J} \\
\tilde{\Xi}\end{array}$ & 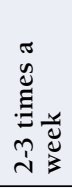 & $\stackrel{\lambda}{\bar{\Xi}}$ \\
\hline Encounter Medicare patients who could not afford their medications? & $\square$ & $\square$ & $\square$ & $\square$ & $\square$ & $\square$ & $\square$ \\
\hline Loan or give away medications to Medicare patients who were unable to afford the medications? & $\square$ & $\square$ & $\square$ & $\square$ & $\square$ & $\square$ & $\square$ \\
\hline Only fill the portion of a prescription that a patient could pay for (e.g., 10 tablets of a 30 tablet Rx)? & $\square$ & $\square$ & $\square$ & $\square$ & $\square$ & $\square$ & $\square$ \\
\hline Contact prescribers to change the current medication to a lower cost medication? & $\square$ & $\square$ & $\square$ & $\square$ & $\square$ & $\square$ & $\square$ \\
\hline File claims for prescriptions with Medicare prescription drug plans that were denied? & $\square$ & $\square$ & $\square$ & $\square$ & $\square$ & $\square$ & $\square$ \\
\hline $\begin{array}{l}\text { Search for free or low-cost medications from manufacturers or community programs for Medicare patients } \\
\text { who could not afford their medications? }\end{array}$ & $\square$ & $\square$ & $\square$ & $\square$ & $\square$ & $\square$ & $\square$ \\
\hline Contact insurance plans to ask if they could cover a medication? & $\square$ & $\square$ & $\square$ & $\square$ & $\square$ & $\square$ & $\square$ \\
\hline $\begin{array}{l}\text { Refer your Medicare patients to the Aging and Disability Resource Centers (ADRC), the Area Agency of } \\
\text { Aging (AAA), or the State Health Insurance and Assistance Program (SHIP) to determine eligibility for } \\
\text { benefits from community programs? }\end{array}$ & $\square$ & $\square$ & $\square$ & $\square$ & $\square$ & $\square$ & $\square$ \\
\hline Advise Medicare patients to schedule an annual wellness visit with their healthcare provider? & $\square$ & $\square$ & $\square$ & $\square$ & $\square$ & $\square$ & $\square$ \\
\hline
\end{tabular}

continued on next page 


\section{How Do Pharmacists Assist Medicare Beneficiaries with Limited Income? A Cross-Sectional Study of Community Pharmacies in Alabama}

\section{APPENDIX Study Survey (continued)}

\section{Part II: Awareness and Knowledge of Community Resources and Assistance Programs}

Instructions: The following questions assess your awareness/knowledge of community resources/programs available to the Medicare population. Please check $\nabla$ true, false or don't know for sure for each statement.

\begin{tabular}{|c|c|c|c|}
\hline Statement & $\sum^{\varrho}$ & $\frac{\ddot{n}}{\tilde{\pi}}$ & 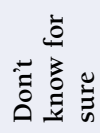 \\
\hline The Medicare Savings Program (MSP) is the same as a Medicare Savings Account. & $\square$ & $\square$ & $\square$ \\
\hline In Alabama, MSP has both income and asset eligibility limits. & $\square$ & $\square$ & $\square$ \\
\hline MSP pays for Medicare Part B premiums. & $\square$ & $\square$ & $\square$ \\
\hline The Low-Income Subsidy (LIS), also known as Extra Help, is sponsored by Alabama Medicaid. & $\square$ & $\square$ & $\square$ \\
\hline In Alabama, LIS has both income and asset eligibility limits. & $\square$ & $\square$ & $\square$ \\
\hline LIS will lower Medicare Part D premiums for eligible individuals. & $\square$ & $\square$ & $\square$ \\
\hline Medicare Part D beneficiaries do not qualify for SenioRx Program. & $\square$ & $\square$ & $\square$ \\
\hline $\begin{array}{l}\text { The State Health Insurance and Assistance Program (SHIP) provides unbiased assistance with Medicare } \\
\text { prescription drug plan evaluation and selection. }\end{array}$ & $\square$ & $\square$ & $\square$ \\
\hline Aging and Disability Resource Centers (ADRC) conduct benefits screenings for MSP, LIS, and SenioRx programs. & $\square$ & $\square$ & $\square$ \\
\hline ADRC conducts benefits screenings for the Alabama Elderly Nutrition Program. & $\square$ & $\square$ & $\square$ \\
\hline Individuals must pay a nominal fee to ADRC to receive their assistance. & $\square$ & $\square$ & $\square$ \\
\hline Annual wellness visits require no copayments from Medicare enrollees if they enroll in Medicare Part B. & $\square$ & $\square$ & $\square$ \\
\hline Medicare Part B pays for Influenza and Pneumococcal vaccines. & $\square$ & $\square$ & $\square$ \\
\hline Medicare Part D plans cover Herpes Zoster vaccine. & $\square$ & $\square$ & $\square$ \\
\hline The late enrollment penalty for Medicare Part D will be added to a person's premium for a maximum of 24 months. & $\square$ & $\square$ & $\square$ \\
\hline
\end{tabular}

\section{Part III: Continuing Education Topics}

Instructions: The Harrison School of Pharmacy is planning to offer free online continuing education programs for pharmacists and pharmacy technicians regarding Medicare benefits, community resources, and Medicare subsidy programs. We hope that the information provided in the continuing education programs will be very useful when you assist Medicare patients. Please indicate the level of interest in each of the following topics.

To what extent are you interested in learning about:

Medicare low-income subsidy programs: Eligibility requirements and benefits

The basics of Medicare: Medicare A, B, C, D

Medicare Part D: current benefits, coverage gap, affordability

Medicare preventive services including annual wellness visits and the "welcome to Medicare" visit

Medicare Part D: star ratings and pharmacy performance

SenioRx: Prescription assistance program

Aging \& Disability Network: Roles of Aging and Disability Resource Centers (ADRC)

Pharmacists' involvement in assisting the Medicare population with limited income

\begin{tabular}{|c|c|c|c|c|}
\hline $\begin{array}{l}\bar{\sigma} \\
\tilde{\sigma} \\
0 \\
0\end{array}$ & $\underset{\Xi}{\stackrel{\Xi}{\Xi}}$ & 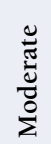 & $\overrightarrow{0}$ & 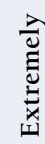 \\
\hline$\square$ & $\square$ & $\square$ & $\square$ & $\square$ \\
\hline$\square$ & $\square$ & $\square$ & $\square$ & $\square$ \\
\hline$\square$ & $\square$ & $\square$ & $\square$ & $\square$ \\
\hline$\square$ & $\square$ & $\square$ & $\square$ & $\square$ \\
\hline$\square$ & $\square$ & $\square$ & $\square$ & $\square$ \\
\hline$\square$ & $\square$ & $\square$ & $\square$ & $\square$ \\
\hline$\square$ & $\square$ & $\square$ & $\square$ & $\square$ \\
\hline$\square$ & $\square$ & $\square$ & $\square$ & $\square$ \\
\hline
\end{tabular}

continued on next page 
How Do Pharmacists Assist Medicare Beneficiaries with Limited Income?

A Cross-Sectional Study of Community Pharmacies in Alabama

\section{APPENDIX Study Survey (continued)}

Part IV: You and Your Practice Site

Instructions: Tell us about yourself and your practice site by checking $\square$ the appropriate boxes.

Education (check all that apply):

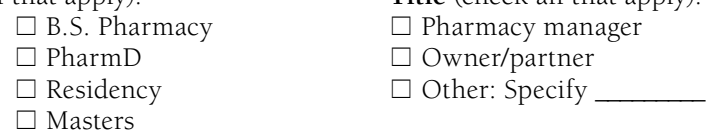

Gender: $\quad \square$ Male $\quad \square$ Female

Race: $\quad \square$ White $\quad \square$ African American $\quad \square$ Asian $\quad \square$ Other

Number of years you have practiced as a pharmacist:

Number of years you have practiced as a pharmacist at this practice site:

At your practice site:

a. Number of staff pharmacists employed (including PharmD):

b. Number of technicians employed:

c. Number of hours per week your pharmacy is open:

d. Average prescription volume per day:

e. Approximate percent of patients who are over 65 years of age:

Full-time equivalent, $40 \mathrm{hrs} / \mathrm{wk}$ (FTEs)

FTEs

Hours

Prescriptions

$\%$

Part V: Your Information

If you would like to be entered in a raffle for a chance to win one of five $\$ 100$ cash prizes, please write your information below.

Name:

Address:

1. Would you like us to notify you that we received your completed questionnaire?

$\square$ No $\quad \square$ Yes

2. Would you like us to send you the aggregate results of this survey?

$\square$ No $\quad \square$ Yes

3. Would you like us to send you information about the free upcoming continuing education programs related to community resources and subsidy programs for limited income individuals?

$\square$ No $\quad \square$ Yes

Please write your email address if you answered "Yes" to at least one of the three questions above: 